\title{
RUSIA Y LAS NUEVAS LEYES \\ DE LA NACIONALIDAD EN LA C.E.I.
}

\author{
IRINA LEDIAJ \\ Jurista del Instituto de Estado y de Derecho \\ Academia de Ciencias de la Federación Rusa
}



Revista de Derecho Político, núm. 38, 1994, pp. 279-292

\title{
RUSIA Y LAS NUEVAS LEYES DE LA NACIONALIDAD EN LA C.E.I.
}

\author{
POR \\ IRINA LEDIAJ \\ Jurista del Instituto de Estado y de Derecho \\ Academia de Ciencias de la Federación Rusa \\ PRESENTACIÓN: \\ TERESA FREIXES SANJUÁN \\ Catedrático de Derecho Constitucional \\ Directora del Departamento de Ciencia Política y Derecho Publico \\ Universidad Autónoma de Barcelona
}

\section{A MODO DE PRESENTACIÓN}

La regulación jurídica de las nacionalidades está constituyendo uno de los puntos "clave» en el proceso de transformación de la extinta Unión Soviética. Dar solución al conflicto de intereses subyacente a la fórmula concreta que pueda adoptarse al respecto se presenta como exigencia inexcusable en la definición del nuevo marco de relaciones interestatales que se configure, tanto entre las antiguas Repúblicas de la Federación Soviética como entre ellas y la comunidad internacional.

En este contexto, el artículo de IRINA LEDIAJ examina los principales problemas que se articulan en torno a la legislación sobre la nacionalidad en la Federación Rusa y otros Estados de la CEI, y los efectos que 
las normas relativas a la igualdad proyectan al respecto (tanto en la propia federación como en relación con el trato que los nacionales rusos reciben en otros Estados surgidos en el proceso de desmembración de la Unión Soviética). Este artículo constituye un ejemplo paradigmático de la dificultad de integrar los principios internacionales que deben regir las relaciones entre los pueblos en el nuevo orden que se perfila, y en este sentido es, evidentemente, coyuntural. La transición en la Europa del Este experimenta rápidas variaciones en concordancia con los continuos vuelcos de la coyuntura politica y económica, las cuales repercuten directamente en el sistema jurídico. Sin embargo, lejos de presentarse como inconveniente, esta transitoriedad constituye un elemento de análisis cualificado en tanto en cuanto expresa las dificultades con que se encuentra esta juridificación, a causa de los conflictos de orden político y económico que le subyacen. $Y$ desde esta perspectiva, el comentario de la Dra. Lediaj mantiene toda su vigencia.

Hay que tener presente, desde otra perspectiva, que la configuración que obtenga la regulación jurídica de las nacionalidades se inserta en un marco mucho más amplio, que constituye a su vez un condicionante de este proceso de cambio. En efecto, en el contexto bajo el cual se está configurando el sistema jurídico de la Federación de Rusia, es necesario remarcar una serie de cuestiones.

Por una parte, este proceso se inserta en un cambio de concepción jurídico-constitucional de gran envergadura, en el cual se abandona el concepto de "Constitución-balance" propio de la época soviética, con el fín de que el nuevo Estado se configure a partir de una Constitución normativa, actualmente en fase de proyecto, la cual pretende incorporar las estructuras políticas básicas y los derechos de los ciudadanos bajo las coordenadas de legitimación propias de los sistemas democráticos. Es evidente que este proceso de transformación es tanto más difícil cuanto que es necesario superar las diferencias de cultura jurídica derivadas de la concepción soviética del derecho como síntesis histórica, expresión del liderazgo de la clase trabajadora e instrumento de la construcción del socialismo, para asimilar una nueva concepción constitucional que esté en concordancia con los nuevos valores que surgen del actual proceso de cambio.

Desde otra perspectiva, el proyecto de Constitución de la Federación Rusa rompe con todos los principios estructurales y funcionales del constitucionalismo soviético. Tras el golpe de estado de agosto de 1991, queda definitivamente roto el sistema de organización de los poderes alrededor de las 15 Repúblicas federales y 20 Repúblicas autónomas, asumiendo la Federación de Rusia un papel preponderante. La ruptura con el sistema político anterior se plasma también en el proyecto constitucional de la Federación Rusa cuando se instrumenta la separación entre 
los poderes clásicos y se definen los derechos, libertades y obligaciones de la persona y del ciudadano en torno a postulados radicalmente distintos a los que se mantenían en la Constitución soviética de 1977.

El problema de la regulación jurídica rusa de las nacionalidades se inserta, pues, bajo las coordenadas delimitadas por un proyecto constitucional en el que, como consecuencia de la desmembración del federalismo soviético, ha desaparecido la nacionalidad única instaurada por la Constitución de 1936 y mantenida por la de 1977. En este proyecto constitucional, además, partiendo de la Declaración de los derechos y libertades del hombre adoptada por el Congreso de Diputados de la URSS con fecha 5 de septiembre de 1991, la cual remite a la Declaración Universal de Derechos Humanos y los Pactos Internaciones sobre derechos humanos, se configura un sistema de derechos de claro corte occidental, acompañado de garantías jurisdiccionales. La nacionalidad constituye, bajo estas coordenadas, el parámetro para determinar la titularidad de los derechos garantizados por el proyecto constitucional, es decir, que de la nacionalidad que se posea dependerá la posibilidad de gozar de tal o cual derecho, tanto si se trata de un extranjero en Rusia o de un ruso en el extranjero. $Y$, desde esta perspectiva, fácilmente se comprenden los problemas que originan tanto la desaparición de la igualdad de derechos en todo el territorio de la ex Unión Soviética, como la consolidación fáctica del trato desigual que deriva de la formación de ordenamientos jurídicos distintos en los nuevos Estados de la CEI, puesto que no todos ellos reconocen los mismos derechos, ni les atribuyen las mismas garantías, ni adoptan los mismos criterios para regular la titularidad.

El sistema de derechos regulado por el Proyecto de Constitución de la Federación Rusa se articula alrededor de:

1. Las «Reglas Generales», o principios generales de base marcadamente iusnaturalista, encabezados por la proclamación "Los derechos y libertades fundamentales del hombre son naturales e irrenunciables y le pertenecen desde su nacimiento". En estas «reglas generales» se reconoce que los derechos y libertades pueden ser ampliados a nivel legislativo, que pueden tener los límites derivados de la propia Constitución así como de la ley (siempre y cuando tenga la finalidad de defender el orden constitucional, la moral pública y los derechos de los demás), que todos son iguales ante la ley $y$ tienen derecho a igual defensa por la ley, así como a la igualdad en derechos y libertades, que el ejercicio de los derechos no puede perturbar los derechos de los demás ni ocasionar daños al bienestar social ni al medio ambiente, $y$, por último, se prohíbe la utilización de los derechos para justificar traslados forzosos o destruir el orden constitucional o la paz.

2. La regulación de la ciudadanía, destacándose al respecto la prohibición de ser privado de la misma y la aceptación de distintas ciu- 
dadanías en las Repúblicas federadas compatibles con la ciudadanía federal rusa, así como la igualdad de derechos y obligaciones entre todos los territorios de la Federación (salvo si la propia Constitución, una ley federal o los tratados internacionales dispusieran excepciones) y el reconocimiento del derecho de asilo.

3. El reconocimiento de derechos y libertades civiles y políticos, entre los cuales se encuentran el derecho a la vida (con la "aspiración" de abolir la pena de muerte progresivamente, estableciéndose como medida transitoria su establecimiento excepcional sólo por sentencia en juicio con jurado), la prohibición de torturas y malos tratos así como la necesidad del consentimiento para someterse a "experimentos" de cualquier clase, la libertad e inviolabilidad personal garantizada por control judicial, el derecho al honor y a la intimidad de la vida privada, la inviolabilidad de la correspondencia y comunicaciones, el acceso al conocimiento de todo tipo de documentos que afecten a los derechos y libertades de las personas, la inviolabilidad del domicilio garantizada también por la necesidad de resolución judicial para entrar en las viviendas, la libertad de circulación y entrada y salida de los límites territoriales federales, la libertad ideológica o religiosa y de expresión e información con los límites que deriven de ley federal para proteger la vida íntima o la moral social o los secretos de estado, el derecho a la utilización de la lengua materna, el derecho a la participación política a través del sufragio universal en condiciones de igualdad de acceso, el derecho de reunión y manifestación, la libertad de asociación y el derecho de petición.

3. Los derechos y libertades económicos, sociales y culturales, basados en la libertad económica a través del derecho de propiedad, del derecho a la libre empresa y del derecho al trabajo libre. Se reconocen también bajo esta rúbrica el derecho a la defensa de la salud, incluyendo la ayuda médica, gratuita para los ciudadanos de la Federación Rusa; el derecho al medio ambiente, a la seguridad y protección social, el derecho a una vivienda bien acondicionada garantizado a través de la acción de los poderes públicos, el derecho a la educación y la libertad de enseñanza y, por último, la libertad de creación artística, técnica e investigadora, así como el derecho a la participación en la vida cultural.

4. Las garantías de los derechos y libertades, instrumentadas a través del control jurisdiccional, de la negación de fuerza jurídica de los actos que violen los derechos y libertades legales y de la inadmisión de pruebas obtenidas con infracción de ley. Todos los derechos anteriormente descritos, tanto los civiles y políticos como los económico-sociales, gozan, en este Proyecto de Constitución, de garantía judicial. Para el aseguramiento de esta garantía en el Proyecto se reconocen el derecho a la defensa judicial garantizado por el Estado a través del auxilio jurídico gratuito que se regu- 
le legalmente; el derecho de acceso a un tribunal competente, independiente e imparcial; la presunción de inocencia, acompañada del principio "in dubio pro reo"; el derecho a la doble instancia judicial, la no retroactividad de las leyes penales y el derecho a no declarar contra sí mismo; el derecho a no ser demandado repetidamente por la misma infracción de ley.

El Proyecto de Constitución de la Federación Rusa pretende articular, en consecuencia, un verdadero sistema de derechos, en el que el reconocimiento de los mismos está acompañado de los instrumentos de garantía propios de la normatividad que se pretende para la propia Constitución. En él se observa que, salvo en lo que dispone con relación a la atención médica, no existen exclusiones en la titularidad de los derechos con relación a los no nacionales. Sin embargo, la existencia, por una parte, de minorías que no tienen atribuida la nacionalidad federal rusa en el interior de la propia Federación y, por otra, de nacionales rusos en otros estados de la CEl a los que no se les reconoce el ejercicio de determinados derechos como consecuencia de su nacionalidad, con el agravante de la constatación de discriminaciones por razones étnicas o culturales en la atribución o denegación de la nacionalidad, constituye una fuente de conflictos, los cuales son analizados en el artículo de la Dra. Lediaj que con este comentario se presenta.

Irina Lediaj es Jurista del Instituto de Estado y de Derecho de la Academia de Ciencias de la Federación Rusa. Cursó los estudios superiores en la Universidad Estatal de Relaciones Internacionales de Moscú y se doctoró en el Instituto de Estado y de Derecho. Como colaboradora científica de este Instituto, se ha especializado en Derecho Constitucional extranjero, así como en cuestiones de responsabilidad penal según el Derecho Internacional. Actualmente trabaja en temas referidos a los derechos fundamentales de la persona en las distintas legislaciones y al desarrollo de los sistemas de garantías y defensa de los derechos humanos a nivel internacional. Su comentario a las leyes sobre la nacionalidad en la CEI, además de insertarse en las coordenadas propias del análisis jurídico, presenta el interés suplementario de estar realizado a partir de un conocimiento efectivo de las raíces y las distintas manifestaciones de la problemática que en el mismo se plantea.

Agradezco a la Dra. Lediaj el envío de estas interesantes reflexiones, y al Profesor Juan José Cano-González la traducción que ha efectuado de las mismas y la documentación que me ha proporcionado sobre el Proyecto de Constitución de la Federación Rusa, así como a la Revista de Derecho Político, que ha tenido la amabilidad de incluir esta publicación en el monográfico sobre la transición en la Europa del Este.

Bellaterra, diciembre de 1992. 


\section{RUSIA Y LAS NUEVAS LEYES DE LA NACIONALIDAD EN LA C.E.I. ${ }^{1}$}

Se puede afirmar, sin exagerar, que para los habitantes de Rusia, e igualmente para los millones de personas residentes en los vecinos Estados independientes y al otro lado de los límites de la antigua Unión de Repúblicas Socialistas Soviéticas, la Ley sobre la nacionalidad en la Federación Rusa, aprobada en noviembre de 1991, tiene un enorme significado. En el preámbulo de la Ley se señala especialmente que la nacionalidad es una relación estable de derecho de la persona con el gobierno fundamentada en el respeto y reconocimiento de la dignidad, de los derechos fundamentales y de las libertades de la persona. Aquí ya se indica que la Ley está llamada a garantizar el cumplimiento de normas y principios de Derecho internacional y de la Constitución de la Federación Rusa, referidos a la nacionalidad y a los derechos de la persona, y también a la obligación que tiene Rusia de garantizar la defensa y la protección de sus ciudadanos que se encuentran fuera de sus fronteras. De este modo se refuerza en la Ley lo fundamental destinado al instituto de la nacionalidad, es decir, a la defensa por el Estado de los derechos y libertades de sus ciudadanos. Es importante subrayar que lo dicho está conforme con lo que se entiende por nacionalidad y que recibe la mayor difusión en la doctrina moderna, en la legislación y en la puesta en práctica de los derechos y libertades en muchos países del mundo. La nacionalidad se afirma aún más como uno de los derechos fundamentales del hombre. Sobre esto testimonia, por ejemplo, una de las autoridades reconocidas en la esfera de los derechos humanos, el jurista y profesor austriaco Félix Ermakora, miembro de la Comisión Europea de los Derechos Humanos en el Consejo de Europa. Este autor afirma que, aunque en el Derecho Internacional actual no hay una norma especial que reconozca la nacionalidad con el carácter de uno de los derechos fundamentales, sin embargo la nacionalidad actúa como condición indispensable, como una conditio sine qua non de reconocimiento de toda una serie de derechos y libertades, y entre ellos el principio de igualdad. Efectivamente, la relación es aquí directa e inmediata, ya que el principio de igualdad, como derecho del ciudadano, garantiza el sufragio universal y la protección de las minorías nacionales, así como también protege contra la discriminación y establece la prohibición de extraditar a los propios nacionales y, en definitiva, prohíbe los privilegios conforme al principio de igualdad de todos los ciudadanos ante la ley. Para muchas constituciones modernas, este principio se sigue en la separación característica de los titulares de derechos y libertades en dos categorías fundamentales. Se ofrece a los ciudadanos un

1 Traducido del ruso por Juan José Cano-González, Profesor de la Facultad de Derecho (Universidad Pompeu Fabra). 
mayor volumen de derechos y libertades en relación a los restantes, incluyendo a los extranjeros residentes en el territorio del Estado dado, permitiéndose excepciones aisladas. En cuanto al enfoque ruso para la solución de este problema, se fundamenta en el principio de igualdad de derechos que recibió la consolidación en el artículo 35 de la vigente Constitución de la Federación Rusa. En él se dice: "A los ciudadanos extranjeros $y$ personas sin nacionalidad se les garantizan los derechos y libertades previstos por la ley, incluyendo el derecho de recurrir al juez y a otros órganos del Estado para la defensa de los derechos personales, patrimoniales, familiares y otros que le pertenezcan". Una nota análoga reproduce y contiene el artículo 6 de la Declaración de los Derechos y Libertades de la Persona y del Ciudadano, que fue adoptado por el Soviet Supremo de la Federación Rusa el 22 de noviembre de 1991, es decir, casi simultáneamente a la ley sobre la nacionalidad de la Federación Rusa, y que aparece como un importante documento legal que afirma los derechos y libertades fundamentales como valor superior de la sociedad y del Estado.

¿Cuáles son los principios y normas más importantes de la ley rusa sobre la nacionalidad y cómo se corresponden con las normas internacionales y con la práctica de otros paises civilizados en la rama de la regulación jurídica de la nacionalidad? Respondiendo a estas preguntas, trataremos de demostrar su diferencia con la última ley de la Unión del 1 de junio de 1990 sobre la ciudadanía en la URSS y también de las leyes adoptadas por las Repúblicas independientes incluidas en la composición de la antigua Unión. La novedad o reforma más democrática consiste, sin duda, en la prohibición de la privación de la nacionalidad: "Nadie puede ser privado de su nacionalidad o del derecho a cambiar su nacionalidad". Esta norma tiene para nuestra sociedad y sus ciudadanos un significado especial, pues excluye en el futuro la posibilidad de utilizar esta medida para luchar contra las ideas distintas, con el objeto de perseguir a los adversarios políticos y de introducir el temor en la sociedad, que fue característico de nuestro Estado durante los setenta largos años de su historia. La práctica antidemocrática de privación de la nacionalidad se acompañó asimismo con la aplicación, en calidad de medida represiva, de la deportación de los propios ciudadanos. Por todo el mundo son conocidos los nombres de notables personajes de la cultura de la Unión Soviética, como A. Solzenitsyn, I. Brodsky, S. Rostropovich, G. Vishnevskaia, V. Bukovski y muchos otros, que, privados de la ciudadanía de la URSS, fueron expulsados por la fuerza de sus fronteras. Semejante práctica pisoteó brutalmente los Tratados internacionales sobre los derechos humanos, muchos de los cuales habian sido ratificados también por la Unión Soviética. Así, el artículo 15 de la Declaración Universal de los Derechos Humanos establece que nadie puede ser arbitrariamente privado de la nacionalidad; en el Convenio Internacional de los 
casos de apatridia se dice que no se puede privar a la persona de su nacionalidad si tal privación le convierte en apátrida (art. 8, p. 1); en el artículo 3 del Complemento del Protocolo adicional número 4 del Convenio Europeo de los Derechos Humanos se mantiene una norma especial sobre la prohibición de deportar a sus ciudadanos del territorio del Estado. Análogas prohibiciones las encontramos en las Constituciones de muchos Estados (República Federal de Alemania, art. 16; España, art. 11, p. 2) y en leyes sobre la nacionalidad (Austria, Ley sobre la Nacionalidad de 1985).

Rechazando la institución antidemocrática de privación de la nacionalidad y deportación, el legislador ruso puso nuestra legislación en concordancia con las normas internacionalmente reconocidas de Derecho internacional.

Es necesario apuntar tal mérito a la Ley rusa, tanto por el amplio fundamento para la adquisición de la nacionalidad como por la fuerza de su reconocimiento en el nacimiento, en el procedimiento de registro, en el resultado de su recepción, en el restablecimiento de la ciudadanía por medio de la opción (elección) en presencia de cambios territoriales, etc. De esta relación desearía destacar especialmente que, por muchas razones, permite corregir las injusticias admitidas al poder soviético durante muchos años en relación a cientos de miles de ciudadanos rusos que constituyen el honor y el orgullo de Rusia. Sin embargo, fueron arrojados por la fuerza después de la Revolución de Octubre, durante y después de la Segunda Guerra Mundial. Hoy, la nueva ley abre la posibilidad de la libre elección a todos los que quieran restablecer su nacionalidad rusa. En relación con esto tiene especial significación el punto e) del artículo 18, por el cual use reconocen como de las Repúblicas Socialistas de la Federación Rusa a los ciudadanos extranjeros y personas sin nacionalidad, independientemente de su lugar de residencia, si ellos mismos o uno sólo de sus parientes por línea directa ascendente hubieran tenido la nacionalidad rusa (ciudadanía) por nacimiento...".

Las condiciones de aceptación dentro de la ciudadanía rusa se han formado en una clave liberal óptima: en la ley de censos están previstos los plazos para los extranjeros (tres años de residencia inmediata antes de la demanda de solicitud o cinco años completos) considerablemente más bajos que los plazos análogos en otras Repúblicas (diez años en Moldavia) o en países occidentales (Suiza, doce años; Dinamarca, siete años; República Federal de Alemania, diez años, etc.).

Habiéndose reforzado el proceso de soberanía de las antiguas Repúblicas de la desintegrada Unión Soviética, las exaltaciones nacionalistas, aunque con distintos grados, se acompañan con discriminaciones $y$ 
restricciones de derechos y libertades directas e indirectas a los residentes no indígenas de estos territorios. Su situación se complica mucho más en la relación jurídico-social, pero es alli, donde los conflictos internacionales se transforman en abiertos enfrentamientos bélicos, donde los más importantes derechos fundamentales, el derecho a la vida, la inviolabilidad de la persona y el domicilio, la defensa del honor y de la dignidad nacional, se exponen a una amenaza permanente.

Como es sabido, más de veinticinco millones de rusos que habitan fuera de los límites de Rusia propiamente dicha, en las Repúblicas del "entorno inmediato", son considerados en casi todas partes como ciudadanos de segunda clase. Así, en Moldavia son los rusos los primeros que se quedan sin trabajo, especialmente aquellos que no dominan el moldavo, hoy lengua oficial del Estado. En sintonía, el renacimiento del Islam estimula el ánimo anti-ruso en las Repúblicas musulmanas del Asia Central. Como respuesta, en Rusia ha surgido una corriente de refugiados, cuyo número se incrementa continuamente. Ahora mismo hay registrados 238.000 de ellos, pero realmente son muchísimos más. Después de algunos años de ausencia de una específica regulación jurídica, el 19 de junio de 1992 el Soviet Supremo de la Federación Rusa aprobó, finalmente, en primera lectura, una Ley sobre los refugiados y los trasladados forzosos. En ella se establece una importante disposición respecto a que los refugiados y los desplazados forzosos disfruten de los mismos derechos y libertades que los ciudadanos de la Federación Rusa. Asimismo se les garantiza también la manutención temporal y gratuita en los lugares de alojamiento, la percepción de subsidios simultáneos, la ayuda médica gratuita, ayudas para la colocación, adquisición de nuevas especialidades y de aumento de la cualificación profesional, la instalación de jubilados sin familia e inválidos laborales en las instituciones destinadas para este servicio social, etc.

En la Ley de la Nacionalidad de la Federación Rusa, como se la conoce, está prevista una norma de privilegio en relación con los refugiados: los plazos de adquisición o de nacionalización en la Federación Rusa se reducen a la mitad en comparación con otras personas (art. 19, p. 2). Está previsto por la ley el régimen de indemnización de los gastos y el pago de una compensación por la pérdida de los bienes.

La realización de esta importante disposición se cumplirá sobre una base bilateral o por acuerdos multilaterales concluidos por la Federación Rusa con los Estados de los que proceden los refugiados o en los cuales vivieron permanentemente. La Ley previene la posibilidad de apelación judicial por actuaciones de los órganos estatales y de los funcionarios por violación de la legislación sobre los refugiados y los desplazados forzosos. 
En estas condiciones tiene especial significado la circunstancia de que los requisitos de recepción en la ciudadanía rusa están formulados en la ley sobre una amplia base democrática. En el párrafo 1 del artículo 19 se dice que la persona que ha alcanzado los dieciocho años de edad puede solicitar la nacionalización independientemente de su origen, raza o nacionalidad, sexo, formación, idioma, religión, ideas políticas y otras convicciones. Comparándola con legislaciones extranjeras, es evidente una diferencia esencial. En las leyes de muchos paises figuran frecuentemente, como condición para la concesión de la nacionalidad al extranjero, el conocimiento del idioma, la instrucción elemental y las garantías de fidelidad a la Constitución. En Estados Unidos, por ejemplo, se exige, complementariamente a ello, el conocimiento de la Historia americana y la evidencia de "conducta moral estable". Lo cierto es que falta una determinación clara de este concepto. Las últimas exigencias también aparecen como obligatorias en una serie de países escandinavos.

Actualmente, desde el punto de vista legal, la posición de los artículos 4 y 5 adquiere un significado especial. Estos artículos garantizan la conservación de la nacionalidad a los ciudadanos de la Federación Rusa que tienen su residencia fuera de sus fronteras, y a quienes el Estado ruso les garantiza defensa y protección. En el punto 2 del artículo 5 se habla de la posible obligación de los órganos estatales competentes de la Federación Rusa de cooperar con toda su capacidad, y sobre una base de igualdad, para utilizar todos los derechos y libertades establecidas por la legislación de las diferentes Repúblicas o del país de residencia, de conformidad con las disposiciones y costumbres internacionales. En los supuestos que lo requieran, estos órganos están obligados a tomar medidas para el restablecimiento de los derechos, que resultaran violados, de los ciudadanos de Rusia. En el marco del Acuerdo sobre la formación de la Amistad de los Estados Independientes se señala especialmente que, habiéndose suscrito un tal acuerdo, las partes garantizan a sus ciudadanos, independientemente de sus nacionalidades o de sus diferencias, iguales derechos y libertades. Cada una de las partes garantiza a los ciudadanos de la otra, y también a las personas sin nacionalidad, los derechos y libertades, de acuerdo con las normas internacionales reconocidas universalmente sobre los derechos humanos. Tales medidas y mecanismos de defensa se estipulan habitualmente por acuerdos bilaterales o por acuerdos de ayuda jurídica.

Rusia concluyó acuerdos bilaterales con muchos Estados integrados en la CEI y con los gobiernos bálticos. Así, por ejemplo, el 12 de enero de 1991 Rusia y Estonia firmaron un acuerdo sobre las relaciones fundamentales entre Estados en el cual ambas partes se comprometen firmemente a observar las normas internacionales fijadas en los documentos de la ONU sobre los derechos humanos. Se indica, especialmen- 
te, que aceptan obligaciones recíprocas para garantizar a todos los ciudadanos que residen en su territorio el derecho de conservar o adquirir la nacionalidad de aquella o de la otra parte en correspondencia con su libre voluntad. Según esto, parece que no se podría inventar nada mejor. Sin embargo, en Estonia se creó otra situación completamente legal que contradice directamente lo acordado. La ley sobre la nacionalidad crea condiciones desfavorables en extremo para la mayoría de los rusos residentes habituales (cerca de 600.000). A causa de diversas limitaciones, entre otras censo, estatutos, idioma oficial, etc., los residentes rusos, al no recibir el estatuto de ciudadano, se ven privados del derecho a adquirir inmuebles y tierras, a participar en el mismo nivel que los estonios en el proceso de privatización de la propiedad estatal, en cuya formación también pusieron su trabajo. Se les ha separado de la participación en las elecciones al Parlamento, a la Presidencia, de la votación en el referéndum sobre las consultas decisivas para la vida política estatal. En esencia, $y$ esto es totalmente evidente, se cumple el objetivo de la formación de un Estado de una sola etnia ${ }^{2}$. Análoga situación se da en Letonia, en donde el 1 de julio de 1992 se terminó el plazo de naturalización conforme a la Ley sobre la nacionalidad, la cual da preferencia a los habitantes que tenían la nacionalidad de la República de Letonia el 17 de julio de 1940 y a sus descendientes. A otra parte de la población, compuesta por el $48 \%$ (de ellos, un $34 \%$ son rusos) se le priva del derecho a voto en la elección del Parlamento de la República, así como también se le limita la libertad de elegir profesión, colocación, etc.

De esta exposición es importante mencionar que en la ley rusa se permite la doble nacionalidad, es decir, la posibilidad de adquirir o conservar la nacionalidad de la Federación Rusa siendo nacional de otro Estado. Como es sabido, la institución de la doble nacionalidad recibió amplia difusión por los acontecimientos de la Segunda Guerra Mundial y se utiliza extensamente en la práctica de relaciones entre Estados. Al mismo tiempo los Estados, en la medida de lo posible, tienden a prohibir su concesión para evitar los conflictos de leyes que surgen en materia de doble nacionalidad. En la práctica internacional, estas cuestiones se regulan por la vía de conclusión de acuerdos internacionales o de tratados entre Es: tados y de concesión a las personas con doble nacionalidad de un régimen más favorable.

En las antiguas Repúblicas de la Unión, esta cuestión se decide de modo distinto. En la mayoría (Kirguizia, Azerbaiján, Moldavia, Estonia,

2 Las apreciaciones de la autora del artículo se han confirmado en las elecciones parlamentarias y presidenciales realizadas el 20 de septiembre de 1992 (N. del T.). 
Letonia, Lituania) no se permite la doble nacionalidad mientras que la reconocen Ucrania y Bielorrusia.

La posición adoptada por la Federación Rusa, dictada por las singularidades de su desarrollo histórico, demográfico y político pero igualmente por factores psicológico-nacionales, se presenta por completo ponderada y democrática. Con ello se reafirma jurídicamente el principio de continuidad de la nacionalidad rusa, de su apertura para todos los conciudadanos rusos, dispersos por el mundo por vicisitudes de la vida, y para todos los que deseen unirse con sus valores culturales, espirituales y humanos o utilizar su jurisdicción.

En relación con esto, subrayamos especialmente el importante significado que tiene el orden judicial establecido por la ley de apelar todas las decisiones relacionadas con la adquisición, la suspensión y la pertenencia a la ciudadanía de la Federación Rusa, pero también de apelar a las acciones procesales de los funcionarios ante las declaraciones examinadas sobre las cuestiones de la nacionalidad.

De este modo, ante las mínimas violaciones de la ley, la persona interesada tiene derecho a dirigirse al juzgado con su queja. Una vez previsto el mecanismo se puede garantizar la efectividad de la ley y la defensa de los derechos fundamentales. 